\title{
Preparing a law teacher to implement the goals and content of the subject
}

\author{
N.S. Zhdanova ${ }^{1 *}$, and L.N. Aksenova ${ }^{2}$ \\ ${ }^{1}$ Altai State Pedagogical University, Barnaul, Russia \\ ${ }^{2}$ State Humanitarian and Technological University, Orekhovo-Zuevo, Russia
}

\begin{abstract}
The paper examines the features of the training and activities of a law teacher in the context of the Russian legal tradition. The author concludes that teaching law based on the national tradition of legal thinking will provide a high quality of education and the formation of a highly moral legal consciousness of young people.
\end{abstract}

\section{A problem statement}

The rapid deterioration in the quality of the values of our society prompts us to make sufficient efforts to restore the true priorities and the revival of Russian national values in the minds of the people. A return to the space of the Russian legal tradition is possible if the legal culture of the people is increased, primarily through the educational space of the modern secondary and higher school, the main figure of which is the teacher. In modern rapidly changing socio-economic conditions, a comprehensive understanding of the multidimensional nature of legal phenomena and the ability to use the appropriate methodology of the process of teaching law with an optimal combination of traditions and innovations allows us to design the pedagogical process most effectively. When teaching law, a system of spiritual and moral values and attitudes of human behavior is formed, knowledge and skills necessary for an independent life of a person in society are acquired, an understanding of human dignity is brought up, respect for other people, tolerance, the desire to use non-violent means of resolving conflicts, a sense of solidarity and a desire to cooperate with others develops.

Currently, there is and is deepening a number of contradictions related to the legal education of young people: the high need of society and the state in the training of highly qualified legal and teaching staff and the lack of adequate organizational and pedagogical conditions for this; ongoing large-scale legal and pedagogical research and the lack of an adequate effect in improving the quality of training a lawyer and a law teacher; transformation of the process of legal education of students of general education institutions in accordance with objective needs and, at the same time, traditional approaches to their preparation. Therefore, in order to improve the quality of legal education, it is relevant, in our opinion, for the teacher of law to take into account the fundamental foundations of building a legal system in Russia, based on the historical traditions of the Russian people, using in teaching methods corresponding to the type of people's legal consciousness.

* Corresponding author: ipcs-profped@yandex.ru 


\subsection{The objective of the work}

Today, there is clearly insufficient theoretical and methodological support for the process of teaching law in the modern education system: the potential of spirituality and morality is insufficiently used in the process of legal understanding and socialization of the personality of students, educational and educational activities of a law teacher, as well as in the formation of his personal moral character. Basic knowledge of traditional Russian legal thinking will allow a teacher of law to combine the diversity of industry-specific information into a holistic vision of law, create conditions for preventing crisis processes in various spheres of society, the primary of which is a moral crisis, and build a process of teaching law in accordance with Russian legal heritage. The spiritual filling of law by a teacher will create a solid foundation for strengthening legal consciousness as a form of social consciousness.

Fundamental research in the field of legal education and upbringing is carried out by modern Russian scientists. In their works, they raise general issues of teaching law, put forward legal education to the rank of a national idea, study the achievements and problems of training highly qualified legal and pedagogical personnel, organizational and pedagogical conditions for the work of a teacher, the level of legal and pedagogical research, pedagogical effect in improving the quality of training a lawyer. and law teachers, the degree of transformation of traditional approaches to the process of teaching law in educational institutions in accordance with objective needs.

Serious theoretical studies on the role of the teacher in legal education and training are carried out in Altai by such prominent legal scholars as V.V. Sorokin, A.A. Vasiliev. They concluded that the formation of a healthy sense of justice in Russia depends on the study of the peculiarities of the Russian sense of justice, created an integral and scientific concept of the Russian sense of justice, and determined the typological characteristics of the domestic sense of justice. Based on the Russian conservative legal doctrine, they conclude about the importance of the monarchical type of people's legal consciousness in Russia, the importance of the teacher's determination of methods of legal education and training suitable for the population of Russia, the primary formation of high spiritual and moral values of the individual before improving legislation, the orientation of educational institutions to education morally developed personalities $[1,2,3]$. When studying the practical issues of teaching law in educational institutions, it is important to refer to the pedagogical research of Russian methodologists, among whom E.A. Pevtsova, S.A. Morozova, E.K. Kalutskaya [4, 5, 6, 7, 8]. In the works of these authors, there is a rethinking of the goals of studying law in a modern secondary and vocational school, the substantive dominants of the school law course and university courses in law and methods of teaching law, technologies and teaching methods, the task of the teacher choosing effective ways of teaching law with an orientation to new requirements is posed. selection of legal materials for educational and legal courses is carried out on the basis of general didactic theory.

Valuable conceptual provisions of these works are the basis for the teacher's holistic vision of the legal system, the synthesis of history, theory and practice of jurisprudence, spiritual, cultural and moral constants of law, the educational impact of law, which will allow students to form the logic of legal thinking, to understand not only the letter, but and the spirit of laws, to develop the skills of mastering the relationship of legal norms related to different branches of law, abstract, theoretical thinking. Understanding the true principles and specifics of the functioning of law by students will increase the authority of educational and scientific activities of educational institutions and teachers of law.

The first results of the joint work of scientists and practitioners in this direction is the emergence of many directions, concepts of legal training and education, which not only argue, complement each other, but also allow to optimally combine the scientifically 
substantiated content of the methodically developed process of transferring and assimilating scientific and legal knowledge and its result in the form of the ability to systematically replenish knowledge, use it in an innovative, humanistically oriented mode, as well as in the form of a predictive method for modeling practical activities. In the modern educational environment, teachers are developing a system of additional legal education, law schools are being formed, the process of digitalization of law education is taking place, regional experience is systematized, and the geography of research is expanding. At the end of the XX century. - the beginning of the XXI century Russian journals have played an important role in the systematization of the all-Russian and regional experience of legal education.

\section{Materials and the results of the research}

In this regard, the purpose of the study is to show the specifics of the theoretical training and practical activities of a law teacher for the formation of a new type of legal consciousness in a student based on the subject content. The key task is to determine the fundamental foundations of building the legal system in Russia, based on the historical traditions of the Russian people, to consider the influence of foreign law on national legal values, to identify the role of a law teacher in legal training in the context of opposition between the status of jurisprudence and jurisprudence.

However, in the mass practice of teaching law, the pragmatic, utilitarian orientation of legal knowledge prevails, their increasing involvement in the circulation of the consumer society. In place of the system of national legal education, an eclecticism of quasi-legal education has developed, which does not meet the needs of society. With the existing legal education, preference is given to legal technique and legal casuistry, the formation of mainly applied skills, the formalist style of work and the informational, commentary way of teaching prevail, which does not contribute to the formation of a legal worldview, understanding of the principles of law, the spirit of law. Students in such conditions are forced to memorize certain regulations without deep understanding. The context becomes more important than the legal text, law-making is replaced by an arbitrary interpretation of what has already been created, and this reinterpretation of what already exists becomes a predominant type of activity. Excessive pragmatism of education, orientation only to the market approach with its predominance of paid services, regional conjuncture, profitability, narrow specialization, eclecticism of training courses leads to insufficient theoretical training of students, neglect of fundamental science [9]. The existing system of legal education does not satisfy educators-scientists, but educators-commentators with a narrow range of legal culture. The overproduction of insufficiently trained teachers with a specialist, bachelor's, master's degree ultimately discredits the profession of a teacher and teacher. With such "literal" teaching, teachers in practice are unable to explain to students the gaps in law, the operation of custom, non-observance of legislation based on the legal worldview, principles of law, and the spirit of law. As a result, the social and spiritual and cultural role of education decreases, and, consequently, the spiritual and moral training of the teacher. Researchers note that such a Western model of legal education, implanted in Russia, is oriented towards manufacturability and has its own traditions that are not adaptable in domestic conditions [10].

A modern teacher is forced to use the concepts and categories of Western legal theory, which is why much attention is paid to formal law [11], the analysis of individual legal components, and not the functioning of legal integrity, which contradicts Russian legal culture and complicates the development of systemic principles of law. Law curricula tend to tend toward Western "natural law" theory, while law enforcement tends to lean toward positivism. In contrast to the natural law and positivist theory of law, there is a Christian tradition of legal thinking, which expresses the need to restore the continuity of Russian 
religious, philosophical and legal thought $[12,13]$. Opportunities for such a study are provided by a spiritual and cultural approach, rather than a formal legal one, which allows you to focus on the fundamental, spiritual foundations of law, synthesizes various legal phenomena into one, general context, forms a model of law through the worldview and mental foundation. Without understanding the spiritual and cultural foundations of law, all types of legal thinking are doomed to incompleteness, fragmentation.

The life of modern Russian society requires the creation of a special synthetic theory of law that opposes the perception of law as a formal means of standardizing external behavior, where the moral foundations of law are more important than the totality of the norm, since they are based on the domestic cultural tradition. It presupposes not the fragmentation of legal knowledge and the study of narrow practical issues, but the recognition of an integral, multi-level law in the knowledge of their primary source [14]. The process of actualizing national and cultural identity is a condition for the unity of the Russian nation in the modern world, and the teacher has to play an important role in this process. In order to increase educational and educational effectiveness, as opposed to Western legalistic ideology, a teacher of law must approve a legal one based on belonging to a domestic culture, where the idea of individuality and collectivism is at the heart of the world outlook instead of individualism and collectivism, instead of competition and conflict - consent and solidarity the unity of rights, freedoms and duties is balanced by the idea of natural duties inherent in every citizen.

Scientists and practitioners are increasingly pointing out the dependence of the effectiveness of legal education on the use of methods appropriate to the type of people's legal consciousness. Therefore, in order to increase the efficiency of the legal education process, it is recognized as important to find the optimal principles of legal education and upbringing for the population of Russia $[14,15]$. Otherwise, the learners will enter into dissonance with the teaching and the promoted norms of behavior, which can lead to an ever-increasing legal nihilism. Of particular interest is the use of the ideas of Russian conservatives of the 18th - early 20 th centuries. about the legal education of society, the attention to the works of which is growing today at almost all levels of social life. They noted the primacy of the upbringing of a high spiritual and moral culture of the bearer of law and the secondary nature of the formation of theoretical knowledge and applied skills in the field of law. The optimal ways of legal education of society, which would be most suitable for the population of Russia, they considered studying the Russian legal system, teaching historical aspects in Russian law and the basics of people's legal consciousness, since the Russian people do not see absolute value in the law, and sometimes the attitude to the law is refracted through the prism of traditions. Another way is to familiarize yourself with various court proceedings and court decisions.

In this regard, the ethical and legal approach has recently become increasingly popular. Ethical principles are laid down in the basis of the Federal Law "On Education in the Russian Federation" and federal state educational standards in the field of secondary and higher education. At the same time, since the formation of a positive type of legal consciousness and behavior of citizens is influenced by "the qualitative level of upbringing and education in educational institutions of various types and types," Russian Federation". Moreover, in a number of regional laws, similar provisions have been introduced, in accordance with which the state regional policy in the field of education is based on the principles of the priority of the values of democracy, legal culture, education of citizenship, tolerance, respect for human rights and freedoms. At the same time, it is recognized that the Federal Law "On Education in the Russian Federation" excessively fixes organizational and managerial issues, but the initial pedagogical, methodological, moral, humanistic and ethical principles of the formation of the intellectual potential of Russia are insufficient. Ethical and moral principles, although laid down in the third generation FSES, allow us to 
close only some issues. For example, human rights are considered exclusively a legal discipline, therefore they are not included either in philosophy, or in sociology, or in political science, or in social psychology. The standards of the third generation are constantly being updated, but they are focused on the requirements of employers and the practical orientation of professional activity, and in such a context they cannot provide a high quality of education and the formation of high moral legal awareness and spiritual and moral values.

Moral imperatives as components of professional culture are provided in the field of training for legal practice. Thus, the federal state educational standards for the training of bachelors and masters in the direction of "Pedagogical education" provide as the necessary competencies: the ability to conscientiously perform professional duties, to comply with the principles of teacher ethics; the ability to effectively implement legal education. In addition, as a compulsory discipline of the curriculum for the preparation of a bachelor in the direction of "Pedagogical education" is provided "Professional ethics". Thus, university graduates must have a high legal culture based on the dominance of the moral and spiritual values of Russian society. The moral culture of a lawyer is also a guarantee of ensuring spiritual values in the field of lawmaking and law enforcement. In atypical legal situations, when there is no rule of law, the only criterion for making a morally balanced decision by a lawyer is conscience. In this case, the qualitative state of the conscience of a lawyer, and not the perfection of the law, predetermines the spiritual validity of the law enforcement act from the point of view of the highest moral principles - justice and mercy. In this context, the tendencies for the transformation of legal education in Russia into highly specialized training in legal technologies in lawmaking and law enforcement on the basis of the principles of pragmatism, market order, and practical relevance look very dangerous. With this approach, legal education loses its moral context and is emasculated into formal and pragmatic training of legal "techies", prepared only to satisfy the client's interests at any cost, even by giving up their own conscience. Law itself becomes just a technique for protecting the relevant interests, losing its high moral vocation - ensuring peace, justice, helping the weak, strengthening spirituality and statehood. Even more threatening is the tendency to increase the paid system in the training of a modern specialist, which results in a drop in the level of his professional and moral culture and the transformation of legal education, including in state educational institutions, into a kind of profitable business. It is characteristic that legal inflation does not lead to an increase in the rule of law in Russian society.

The state should take care that the law is not limited to an emphasis on external obedience, much more important is to change the way of thinking of people, to foster moral sense and legal awareness, to strengthen conscience. A significant role in this process is played by national institutions for the upbringing of traditions - the church, the family, the school (higher, professional and general education) - through the introduction of various ways to improve legal education: the introduction of training courses and teaching materials into the educational process that provide knowledge in the field of traditional Russian spiritual culture and moral foundations of Orthodoxy, as well as philosophy, history and theory of law, the foundations of Russian law; implementation of vocational guidance for young people with a deep theoretical substantiation of the moral foundations of professional activity.

In the context of an information society and an increase in the volume of information, the reform of the education system found itself in a situation of urgent need to maintain a balance between changes and stability, coordination, and agreement between different levels and forms of education. Therefore, in the learning process, the key figure should not be the student, but the teacher. It is the personality of the teacher that determines the interest of students in the subject being studied and the depth of the studied course. A 
teacher with spiritual and moral principles, extensive scientific knowledge, creative activity, and also "charisma" is the main character of the educational process [16]. It is he who knows and subtly feels the measure in the use of traditions and innovations, knows how to show the required attention and kindness to students on the basis of an individual approach. When the content and intensity of the educational process begin to be established by students and their legal representatives, a situation of absurdity arises.

The key factor in the development of the personal spiritual status of a law teacher is knowledge outside of his narrow professional activity - in the field of Russian literature, art, philosophy, political science, history. Often, modern graduates know more about the specifics of foreign law than the specifics of Russian law and legal traditions of the Russian people. As a result, the lack of knowledge in other scientific areas and spheres of knowledge, the inability to understand the structural features of legal new formations as a result of globalization and to understand their nature show that the teacher of law is a very ordinary person, which, however, does not detract from his high opinion of himself. At the same time, higher pedagogical and legal education is already assessed by society not as the most important social, spiritual and cultural mission, but as a sphere of paid services.

At the same time, the need to accumulate and constantly update knowledge is characteristic of a teacher of any subject, but is especially important for a law teacher: the content of no school or university discipline is updated as quickly as law. This is due to the fact that the subject of study is the continuously changing modern life of society, the state and the individual. Changes in social and educational conditions lead to the highlighting of certain factors of the relevance of teacher self-training. It is obvious that there is a need to radically improve the situation in secondary and higher education on the basis of fundamental training and retraining of law teachers in the field of legal sciences, philosophy and history of law, theory and methodology of teaching law, strengthening the effective and practical orientation of education, implementing modern requirements of the standard and curricula. First of all, the teacher must understand the need for careful adaptation of legal ideas to the national, cultural, civilizational originality of Russian reality, pay great attention to acquainting students with the works of historians and lawyers on this issue, organize the creative independent work of students, and more actively saturate teaching and educational work with facts. actions of common Russian law and the expression of the "spirit" of the law in solving legal issues. In addition, the relevance of teacher training has increased in connection with the modernization of social science education, including legal, and certain problems of the theory and methodology of law acquire a new meaning in modern science. Many previous assessments have undergone profound changes or become diametrically opposed to those that scientists once held.

According to the domestic tradition, legal education should be based on the recognition of the principle of the unity of education and upbringing and include the direct acquisition of knowledge, but not as an end in itself, but as a necessary means of upbringing and personal development. By itself, legal literacy and the availability of legal knowledge, education does not guarantee law and order. Modern researchers also draw attention to the fact that the efforts of the family, society and the state should be aimed not at assimilating legal knowledge, but at instilling spiritual values of the individual, which can become a powerful internal core for high moral and law-abiding behavior [17]. Therefore, attention should be paid to the moral and spiritual education of the individual as the core of the legal consciousness of the individual and the guarantee of the lawful behavior of a person. Therefore, today it is recognized as expedient measures of state policy, which are designed to revive and consolidate the spiritual and moral values of Russian society through the relationship of legal education with patriotic, labor, environmental and other types of education on a common moral basis. Saturation of the educational program with such 
courses as ethics, aesthetics can contribute to the development of the spiritual world of the individual, and at the same time, the legal consciousness of a person.

The pedagogical community recognizes the need to preserve the maximum individualization of teaching, significant theoretical training, providing a high spiritual and moral training of a specialist, a slight differentiation of courses, a wide specialization of educational programs for the development of a wide range of legal culture of a teacher and an understanding of general legal relations and systemic principles of law with pedagogy, didactics and methods. teaching, maintaining a unified legal and pedagogical terminology. The curriculum should also adhere to the elementary principle of teaching "from simple to complex". Curricula should be aimed at forming a student's holistic image of the world in the interconnection and interdependence of the spiritual and moral foundations of the legal system of society with its constant variability.

A new era in legal education today is the development of a holistic technology of the event-based approach in teaching law, which involves active social interaction between the teacher and students in the field of their joint activities in the legal educational space based on the nature-conformity of content and technologies. Therefore, in legal education, the search for points of view that can be shared with others is paramount, the emphasis is shifted from transforming the student's personality to retaining and transforming the sphere "between" the teacher and the student in order to develop the child's personality [18]. The legal facts of the events accompanying the student, in the environment, can be powerful in their emotional coloring and be supported by the practice of real legal relations and actions. In search of the pedagogical optimality of legal education, specialists have turned and are turning to the legal event as a factor of effective influence on the processes of personality formation.

In the field of monitoring and assessing the educational achievements of students in the Russian Federation, significant changes have occurred over the past decades. One of them is the emergence of new forms and methods of monitoring and evaluation. Various standardized forms of identifying and assessing educational achievements of students have become widespread $[19,20]$. However, when teaching humanitarian disciplines, including law, the effectiveness of many forms of assessment is not unambiguous. Thus, testing in teacher education is minimally justified (as a retake of exams and tests, a game element in some practical lessons). A certified teacher trained on tests is lost in the abundance of legislation and, moreover, cannot provide legal assistance in a situation of a gap in law, when it is necessary to reason legally, to derive a fair decision. The Unified State Exam fosters an attitude towards the development of exclusively mechanical memory. In this case, the graduate does not acquire the skill of elementary communication with people, while in his future professional activity it is necessary to be able to convince, prove, motivate, justify. Oral answers at seminars and oral examinations, regular and sufficient communication with the teacher are important here. The passage of numerous case-stady, in which they master cases (exercises created on the basis of empirical experience) and the emphasis is on the collection of ready-made schemes by students for action in strictly defined circumstances - this is Western technology, a vivid legal positivism that domestic legal education has never used. Life is richer than a scheme, and the Russian jurist was taught to follow a reasonable and highly moral logic of life, avoiding a schematic, formal approach to the fate of an injured person.

\section{Conclusions}

Thus, today there is a crisis in the holistic understanding of law, its relationship with fundamental moral principles. Legal force alone is not enough for effective action, therefore moral education is the basis of the general and professional legal culture of a law 
teacher. Historically, the foundations for the construction of the legal system in Russia have been a multilevel, systemic knowledge of legal phenomena based on domestic customs and traditions as primary sources. The primacy of the educational component over knowledge, the formation of theoretical knowledge over applied skills, the formation of law through the worldview and mental foundation of Russian spiritual and moral culture characterized national legal values. In modern conditions of the prevalence of Western legal theory, an emphasis on form rather than content, a decrease in the role of moral constants of law, law itself turns into jurisprudence with its focus on technological effectiveness as a manifestation of the globalization of the world. Modern negative manifestations of globalization in pedagogical education, while teaching the country's main intellectual potential - the teacher, must be minimized in order to preserve and enhance Russian national educational traditions, restore true priorities and revive Russian national legal values, improve the legal culture of the younger generation through the educational space of a modern school. The relationship of legal education with its other types, increasing the role of the ethical and legal approach in legal education and general literacy in related fields of knowledge, including disciplines in the field of Russian traditional spiritual culture in the educational program, strengthening the practice-orientedness of traditional forms and methods of control with an emphasis on communication practices, the use of creative forms of identifying and assessing the educational achievements of students will fill teacher training with effective, logical content.

\section{References}

1. V.V. Sorokin, A.A. Vasiliev, The concept of legal education of the Russian society, 208-210 (Barnaul, 2014)

2. A.A. Vasiliev, Legal education in the light of national traditionalism, Legal thought in education, science and practice, 2, 9 (2013)

3. O.V. Ostapovich, I.Y. Ostapovich, The genesis of legal education in Russia, p. 62-66 (Legal science and education in Russia and Asia. Law teaching method: materials of the I Russian-Asian Legal Congress, 2-3 October, 2014)

4. E.A. Pevtsova, Children's law school: topical issues of organization, p. 38 (Moscow: Chancellor, 2011)

5. S.A. Morozova, Legal education of schoolchildren in modern Russia, Teaching history and social studies at school, 3, 23 (2014)

6. E.K. Kalutskaya, Methodology of legal education in modern schools and the educational potential of law, Teaching history and social studies at school, 3, 45 (2015)

7. V.V. Ryabov, A.A. Sorokin, V.V. Shapoval, Social and humanitarian education in the modern educational space: realities and trends, 75 (2018)

8. A.I. Matveev, Study of issues of law in the course of social studies, Teaching history and social studies at school, 2, 76-80 (2013)

9. V.A. Kumpan, Federal state educational standards of basic general and higher education: problems of conceptual continuity in the information society, Teaching history and social studies at school, 3, 55-62 (2020)

10. S.V. Khomutsov, Spirituality in culture: past, present and future, p. 446-451 (Monography, Barnaul, 2009)

11. F.P. Fursova, From the history of legal education in Russia, Teaching history and social studies at school, 1, 69-72 (2006) 
12. Y.A. Ogorodnikov, About upbringing and education in the coming Russia. The value of faith in pedagogy (based on the works of I. Ilyin), p. 93 (Moscow, 2018)

13. I.L. Solonevich, People's monarchy, p. 115-133 (Moscow: Phoenix, 1992)

14. V.V. Sorokin, The concept and essence of law in the spiritual culture of Russia, p. 2021 (Monography, Moscow: Avenue, 2007)

15. M. Novikov, V. Shvetsov, Development of the Russian education system in the 19th century. and problems of teaching jurisprudence, History and social studies for schoolchildren, 4, 37-52 (Novosibirsk, 2017)

16. V.V. Sorokin, Law and Orthodoxy, p. 253 (Novosibirsk, 2010)

17. A.A. Vasiliev, The concept of legal education in the context of the conservative legal doctrine of Russia, Legal education and science, 3, 11-14 (2012)

18. E.B. Kurkin, Event education - technology of the future, Educational policy, 1 (71), 24-33 (2016)

19. E.M. Ambartsumova, Modern forms of control and assessment of educational achievements of schoolchildren, Teaching history and social studies at school, 1, 51$59(2020)$

20. E.A. Pevtsova, Implementation of the modern doctrine of legal education in Russia, Law and Education, 11, 33-38 (2003) 